\title{
Economía solidaria, cooperativismo y descentralización: la gestión social puesta en práctica
}

\author{
Solidarity Economy, cooperativism and decentralization: social management in practice ${ }^{1}$
}

Pablo Monje-Reyes ${ }^{2}$

\section{Resumen}

Hoy en día se hace cada vez más necesario analizar nuevas formas de organización social, que permitan fortalecer el rol protagónico de actores sociales subalternos. Por tanto, esta publicación tiene como objetivo proponer y desarrollar, críticamente, un debate conceptual sobre economía solidaria, descentralización y cooperativismo, en el marco de la gestión social. El artículo es parte del desarrollo de un marco teórico de una investigación sobre cooperativismo y buenas prácticas en gestión social, descentralización y economía solidaria.

Palabras Claves: Economía solidaria. Cooperativismo. Descentralización. Gestión social.

\begin{abstract}
Nowadays it is more necessary than ever to analyze new forms of social organization, which make it possible to strengthen the protagonist role of subaltern social actors. Consequently, this article aims to critically propose and develop a conceptual debate on solidarity economy, decentralization and cooperativism, in the framework of social management. This article is part of a theoretical framework, that is still in the developmental stage, for research on cooperativism and good practices in social management, decentralization and solidarity economy.
\end{abstract}

Keywords: Solidary economy. Cooperativism. Decentralization. Social management.

\section{Presentación}

Desde hace ya un tiempo se viene buscando nuevas de formas de organización de la economía política, que pretenden salir de las actuales reglas impuestas por el neoliberalismo en nuestra América. Estas nuevas

Artigo submetido em 21 de março de 2011 e aceito para publicação em 04 de agosto de 2011.

${ }^{1}$ El documento es el resultado preliminar, para el año 2010, del proyecto de investigación en Gestión Social: enseñanza, investigación y práctica, financiada por el programa de apoyo a la enseñanza y la investigación científica en administración de la Fundación CAPES - Brasil.

2 Magister en Gestión y Políticas Públicas de la Universidad de Chile; Administrador Público de la Universidad de Los Lagos - Chile; Director Ejecutivo del Centro de Estudios y Análisis de Políticas Públicas CEAPP - Chile. Direccion: Calle Erasmo Escala 2730, CEP 8320000 Santiago de Chile. E-mail: pmonje@vtr.net 
formas de organización económica han surgido a partir de las crisis periódicas del modelo hegemónico y son, por ejemplo, las empresas recuperadas por trabajadores en diversos ámbitos de la producción; sistemas de compras colectivas en barrios o en empresas de cartoneros o recicladores de basura, en las grandes metrópolis de nuestras ciudades. A la vez, se han revivido experiencias históricas de producción, como es el cooperativismo, que ya a mediados de la revolución industrial en Inglaterra se levantaba como una forma de producción alternativa, siendo su principal característica la propiedad real de los beneficios de su producción, ésta en manos de los cooperantes o propietarios de la fuerza de trabajo, y no del dueño del capital. Estas nuevas formas de organización de la producción han ido dando forma al concepto de economía solidaria.

El desarrollo de la economía solidaria ha sido impulsado por el surgimiento de nuevas formas de gestión, la gestión social, que de la misma manera como se ha mencionado en economía, ha sido crítica a las formas de gestión dominantes. La gestión social ha permitido generar una visión alternativa a los modelos de gestión piramidal o gestión empresarial, que conceptualmente y en la práctica se articulan de arriba hacia abajo. La concepción de la gestión social apunta, desde una perspectiva crítica epistemológica, a la organización de la gestión desde abajo hacia arriba. Su característica principal es la horizontalidad en la toma de decisiones y en la definición de los procesos de producción. Por tanto, es igualitarista, democrática y adaptativa al medio socio-cultural. Esta visión de la gestión social es totalmente complementaria a las nuevas formas de organización socio - económica, que hemos mencionado.

Tanto desde la perspectiva de la economía solidaria como de la gestión social, esta publicación tiene el objetivo de proponer y desarrollar, críticamente, un debate conceptual sobre economía solidaria, descentralización y cooperativismo, en el marco de la gestión social, como telón de fondo o de base argumentativa. El artículo constituye el marco teórico en desarrollo para una investigación sobre cooperativismo y buenas prácticas en gestión social, descentralización y economía solidaria, actualmente en curso. ${ }^{3}$

La perspectiva de análisis es de carácter crítico-social. La razones fundamentales de esta opción son: i) el objeto de estudio, vale decir, el cooperativismo, corresponde a estructuras sociales que se contraponen al modelo epistemológico dominante en la sociedad actual; y ii) la perspectiva crítico social permite realizar un análisis descriptivo de la realidad, de carácter empírico - analítico, e interpretativo, de carácter histórico hermenéutico, (APEL, 1975, p. 380-381; HABERMAS, 1984, p. 175-176). Por tanto, permite explicar las principales características del modelo de gestión social aplicado al objeto estudiado, y analizar e interpretar sus resultados en el marco de dominación actual. Todo esto permite desarrollar premisas para definir aprendizajes y transferencias de conocimiento a otros actores sociales (políticos, sociales, económicos e intelectuales) con el fin de avanzar en la construcción de una nueva hegemonía en campo de la gestión, la economía y la descentralización del Estado.

El documento se estructura de la siguiente manera: i) un análisis de los conceptos de economía solidaria y descentralización, y su articulación conceptual; ii) cooperativismo y su debate teórico, iii) la gestión social como articulación y propuesta de modernización de la sociedad democrática, en donde la ciudadanía es protagónica; y iv) síntesis e integración de los conceptos analizados.

\section{Economía Solidaria y Descentralización}

El desarrollo del capitalismo en su fase neoliberal globalizada, dominante a nivel de los países y regiones periféricas de América Latina, ha hecho preguntarse a distintos actores políticos, sociales y culturales, ¿cómo

3 La investigación se denomina "La cooperativa de agua potable rural Hospital-Champa. Un estudio de caso de gestión social”, y está siendo realizada por el autor en una comunidad rural del Área Metropolitana de Santiago de Chile (2010-2012). 
revertir esta fase de dominación del capitalismo, tan voraz con nuestras sociedades y naturaleza? La respuesta que se ha ido generando, en diversos hemiciclos, es el nacimiento del concepto de economía solidaria y el resurgimiento del cooperativismo. Ambas concepciones han ido dando respuesta a la exclusión social y sobreexplotación de la naturaleza en nuestras regiones, que el modelo neoliberal ha dejado como secuelas, muy difíciles de borrar en nuestras sociedades.

La concepción de economía solidaria es una alternativa que puede darse al interior del capitalismo dominante. Consiste en fundar las bases de un modo de producción con otros principios, por supuesto distintos a los de la explotación de los obreros, que busca el objetivo maximizar las tasas de ganancia y en donde la naturaleza es un insumo para producir riqueza, como se practica en la actual fase neoliberal. Los principios de la economía solidaria, como su nombre lo dice, son parte de la solidaridad entre trabajadores que han sido explotados, y que perciben y toman conciencia de que su capacidad de generación de riqueza ha beneficiado sólo a los dueños del capital. Por tanto, la economía solidaria descansa, en cuanto a base social, en la sociedad civil, en la crisis de las relaciones de trabajo-capital, en el aumento de la exclusión social en la adquisición de bienes y servicios por parte de una gran masa de personas, y en la sobreexplotación de los recursos naturales. Esto ha llevado a que las bases sociales colectivicen la producción de bienes y servicios, reorganizando las formas de producción, por medio de la creación de cooperativas, pequeñas empresas autogestionadas y de trabajo comunitario de producción material, y/o servicios de consumo. Con esto se instala un segundo principio, de la igualdad entre pares sobre una propiedad colectiva, que se pone en práctica cuando debe ser gestionada por medio de formas y métodos democráticos para la toma de decisiones.

La economía solidaria puede ser definida "como un conjunto de actividades económicas de producción, consumo y crédito organizadas sobre la base de formas de autogestión, en donde la propiedad del capital es de carácter colectivo y la toma de decisiones es democrática en donde todos los miembros de la entidad productiva participan directamente" (SINGER, 2003) En esta definición todos los trabajadores son propietarios del negocio, ya que el capital es su propia capacidad transformación material, y todos trabajan para producir. Por tanto en esta forma de producción, la división capital-trabajo tiende a desaparecer.

La definición anterior ha sido debatida desde perspectivas congruentes entre sí, pero que perfilan variantes conceptuales interesantes. La concepción de economía popular y solidaria plantea que una nueva forma de organización económica de la sociedad debiese estar dada por medio de unidades productivas, que tengan como práctica cotidiana compartir el trabajo de producción, en términos autogestionarios y solidarios (RAZETO, 1993), términos entendidos como parte de un aprender haciendo: “... entonces aprenden unos de otros y, sobre todo, se refuerzan recíprocamente en sus motivaciones. Los que van construyendo economía de solidaridad, buscando superar su pobreza y marginación, se encuentran con quienes lo hacen buscando una sociedad más justa y fraterna" (RAZETO, 1999), lo que lleva a desarrollar la economía solidaria.

Otra variante es la concepción de economía del trabajo, que se define como un conjunto integrado de actividades económicas de producción y reproducción, dirigidas por los trabajadores, teniendo como recurso central el trabajo (CORAGGIO, 2000 e 2003). Este mismo autor amplía esta concepción a la definición de economía social. Esta vertiente -bajo diversas variantes - ve la posibilidad de desarrollar una visión socioeconómica, en que los agentes económicos no son escindidos de sus identidades sociales, mucho menos de su historia y de su incrustación en el mundo simbólico e institucional que denominamos cultura. Al concebir la economía como inseparable de la cultura, la Economía Social entiende que la sociedad no es un espacio de acción constituido por individuos utilitaristas que buscan ventajas materiales, sino por individuos, familias, comunidades y colectivos, de diverso tipo, que se mueven dentro de instituciones decantadas por la práctica, o acordadas como arreglos voluntarios, que actúan haciendo transacciones entre la utilidad material y valores de solidaridad y cooperación, limitando (no necesariamente anulando) la competencia (CORAGGIO, 2002). La Economía Social se caracteriza porque produce sociedad, y no sólo utilidades económicas; porque genera valores de uso para satisfacer necesidades de los mismos productores o de sus comunidades -generalmente de base territorial, étnica, social o cultural- y no está orientada por la ganancia y la acumulación de capital sin límites; porque vuelve a unir producción y reproducción, al producir para satisfacer, de manera más 
directa y mejor, las necesidades acordadas como legítimas por la misma sociedad. Sin embargo, para ser socialmente eficiente, a la Economía Social no le alcanza con sostener relaciones de producción y reproducción de alta calidad. Su fundamento es, sin duda, el trabajo y el conocimiento encarnado en los trabajadores y sus sistemas de organización, pero la base material de la economía exige contar con medios de producción, crédito, tener sus propios mercados, o competir en los mercados que arma el capital (CORAGGIO, 2002).

Un variante que también se ha discutido en la última década, es el concepto de Economía Popular, que refiere al conjunto de actividades económicas y practicas sociales de desarrollo, realizadas por los sectores populares con su propia fuerza de trabajo y sus recursos disponibles, en búsqueda de la satisfacción de sus necesidades básicas, tanto materiales como no materiales (ICAZA, et al., 2003). Complementariamente a esta definición está la concepción de Economía Popular Solidaria, que define que el desafío está en que los factores de desarrollo social, económico, político y cultural debe emerger de abajo hacia arriba, abierta al mundo, con identidad propia, y que apuesta a establecer un equilibrio entre la distribución y la justicia. Una economía que comience a difundir y mostrar otros valores con que la economía actual no dialoga (ARROYO, 2003).

En síntesis, cada uno de los conceptos de economía solidaria, popular, social, del trabajo, son desarrollos epistemológicos que se interconectan y articulan entre sí, en base a una discusión crítica de la actual concepción dominante de la economía neoliberal. De hecho, las concepciones esgrimidas se elevan desde la noción de otros valores políticos, ideológicos, éticos y estéticos, que colocan en el centro al ser humano, como objetivo del desarrollo económico, social y cultural. Se centran en la concepción del trabajo como fuerza transformadora de la realidad, la igualdad, la cooperación y la solidaridad, como principios de organización y desarrollo productivo de las comunidades locales. No obstante, esta definición de economía solidaria en términos de síntesis conceptual, se encuentra en desarrollo epistemológico aun no concluido. Por el contrario, requiere de aportes que vienen de otras disciplinas como la ecología, los estudios culturales, los aportes de la administración, la sociología e inclusive la historia local. Para lo cual se requiere de una gama de estudios empíricos, que permitan ir nutriendo cada vez más el debate epistemológico. De hecho, estudios de esta última década plantean ciertas tesis de trabajo sobre economía solidaria (SANTOS, 2002, p. 64-73) que se deben tener presente a la hora de considerar los avances conseguidos en su conceptualización. Nueve a lo menos tienen importancia para el debate:

1. las alternativas de producción no sólo deben ser económicas: su potencial emancipatorio y sus perspectivas de éxito dependen, en buena medida, de la integración que consigan en procesos de transformación económica y procesos culturales, sociales y políticos;

2. el éxito de las alternativas de producción depende de su inserción en redes de colaboración y de apoyo mutuo;

3. las luchas por la producción alternativa deben ser impulsadas dentro y fuera del Estado;

4. las alternativas de producción deben ser en términos de escala comunitaria;

5. la radicalización de la democracia participativa y de la democracia económica son dos caras de la misma moneda;

6. existe una estrecha conexión entre las luchas por la producción alternativa y las luchas contra la sociedad patriarcal;

7. las formas alternativas de conocimiento son las formas alternativas de producción;

8. los criterios para evaluar el éxito o el fracaso de las alternativas deben ser gradualistas e inclusivos;

9. las alternativas de producción deben tener relaciones de sinergia con otras esferas de la economía y la sociedad. 
Estas tesis permiten comprender que el concepto de economía solidaria está en proceso dialéctico de elaboración, ya que al contrastar sus principios con la realidad política y social, se van asumiendo nuevos elementos que permiten mejorar su definición, y por tanto su desarrollo. Es importante destacar que parte de las definiciones que se elaboran comprenden, como principal actor de la economía, a los sectores sociales que quedan fuera de los beneficios del mercado y de las políticas públicas del Estado. Aún más, una parte de estos relevamientos conceptuales nace a partir de la observación práctica de experiencias de recuperación de empresas, que en crisis del capitalismo quebraron y fueron tomadas por los trabajadores y gestionadas por ellos, o de acciones colectivas como son emprendimientos sociales llamados "comprar juntos", "ollas comunes", las empresas sociales de recolectores y recicladores de desechos, y las cooperativas de servicios o productivas, entre otras experiencias.

De esta manera, la economía solidaria tiene implícita la concepción más genuina y avanzada de descentralización económico política de la sociedad y del Estado. Por una parte, la actividad económica se sustenta en la organización socio-política, en la cual se decide democráticamente qué hacer en conjunto. Por otra, tampoco depende del Estado, ya que su matriz de financiamiento de inversión y capital están determinadas por la participación de sus socios, en tanto estos son propietarios de fuerza de trabajo. Es decir, estamos frente a una verdadera descentralización económico social - productiva, que el Estado capitalista en la actualidad no logra alcanzar, ya que para su sobrevivencia requiere de la centralización de la economía, para el uso de su excedente en beneficios de los dueños del capital.

Impulsar formas de producción que integren los principios de la economía solidaria, es clave para un proceso de reforma y cambio del sistema económico actual. Para ello es necesario explorar este tipo de formas producción, como es el caso del cooperativismo.

\section{El Cooperativismo y su Debate Conceptual}

Una síntesis de la praxis y la concepción de la cooperación aparece desde las primeras acciones colectivas de los seres humanos, que responden a una vocación natural o búsqueda de protección y amparo, frente a las fuerzas de la naturaleza y la acción de otros hombres. Los registros históricos de la humanidad muestran que el hombre no coopera por ser mejor o para establecer fines inmediatos, sino como una necesidad de su existencia y desarrollo. La cooperación es la base fundamental de la cultura de la humanidad y forma parte de su esencia, lo que hace de ella un factor de transformación, en términos dialécticos, entre las acciones del individuo y el colectivo.

Cooperar significa trabajar juntos, actuar en grupo con base en los principios de la integración y la solidaridad. La cooperación es, como afirma Marx en el Capital (volumen 1, 1867, ed. 1990): "la forma de trabajo de muchos obreros coordinados y reunidos con arreglo a un plan en el mismo proceso de producción o en procesos de producción distintos, pero enlazados". Aunque Marx aplica esta definición al proceso de producción, es totalmente válida para otras actividades que realizan los hombres, teniendo como base el trabajo. Al respecto, es importante dejar claro que la cooperación es ante todo un hecho de la realidad cotidiana, inmerso en la esencia misma de la socialización económica, política y cultural de la especie humana.

Sin cooperación no hay trabajo colectivo valorable, pues este tiene su fundamento económico, en tanto trabajo socialmente útil, que permite alcanzar un nuevo estado de acción de la fuerza de trabajo y la propiedad entre individuos. Por eso, cooperación y riqueza se encuentran íntimamente relacionadas. La cooperación nace del trabajo, pues con cooperación entre pares es posible el trabajo social organizado, y su resultado es la generación de riqueza o excedente económico.

Una concepción de la cooperación define que: "cuando el hombre se asocia, lo hace para cooperar. De tal manera que en un estricto análisis podemos afirmar que la cooperación, al ser un valor de orden vital, no 
puede estar en contradicción con ninguno de los propósitos que inducen al hombre a lograr sus objetivos vitales dentro de los que se encuentran la consolidación de una sociedad equitativa y libre, esto es la sociedad sin clases" (AGINTZARI, 2003). Entendiendo que el elemento distintivo de una sociedad sin clases es la cooperación entre pares, como su organización democrática, integradora y solidaria, ya que, si no se presentan estos elementos, se estaría frente a formas autoritarias e inclusive dictatoriales para conseguir cooperación.

El valor fundamental del cooperativismo es la cooperación en términos de los principios de la integración, la solidaridad y la democracia social. En ella funda su finalidad, que son el ennoblecimiento y la liberación de la sociedad, es decir, de una sociedad realmente emancipada y socialmente integrada.

La cooperación es un hecho y un valor del ser humano. En tal sentido, requiere de un fin que justifique su existencia. Podemos clasificar estos fines como fines sociales, fines económicos y fines políticos.

En términos de fines sociales, la cooperación se enmarca en la búsqueda de la transformación integral de la sociedad, por medio del trabajo cooperativo y el desarrollo libre de todas las potencialidades de los individuos en comunidad. Desde el punto de los fines económicos, la cooperación viene a ser el centro entre la satisfacción de necesidades materiales y simbólicas, que tiene el hombre y la mujer; la relación de la naturaleza, la ciencia y tecnología; y la capacidad de transformación que tiene la fuerza de trabajo, generando un equilibrio articulado entre todos los elementos. Los fines políticos remiten a la democracia de abajo hacia arriba, en donde los cooperados participan de las decisiones del colectivo y de sus acciones.

\title{
Cooperativismo en "América" precolombina
}

En términos históricos, el cooperativismo en nuestra América es anterior a los procesos de conquista. Existen antecedentes que muestran que las economías de los pueblos precolombinos eran eminentemente de carácter cooperativo, tanto en su organización social como en la producción. Al revisar algunas experiencias históricas de los pueblos precolombinos, se reconoce que "las formas de trabajo indígena de carácter solidario y orgánica, la organización colectivista, regida por los Inkas sacaban toda la utilidad social posible de esta virtud de su pueblo, El trabajo colectivo, el esfuerzo común, se empleaban fructuosamente en fines sociales" (MARIATEGUI, 2009 Ed.). Se debe tener en consideración que esta forma de organización político-social de los Inkas fue altamente jerarquizada y de carácter autocrático para su contexto histórico, pero su potencial estaba dado por su sentido de protección de la comunidad, que se caracterizaba porque la

\begin{abstract}
"propiedad colectiva de la tierra cultivable por el ayllu o conjunto de familias emparentadas, aunque dividida en lotes intransferibles; propiedad colectiva de las aguas, tierras de pastos y bosques por la marca o tribu, o sea la federación de ayllus establecidos alrededor de una misma aldea; cooperación común en el trabajo; apropiación individual de las cosechas y frutos" (UGARTE, apud MARIATEGUI 2009 Ed., p. 71).
\end{abstract}

Ante las experiencias históricas de los pueblos precolombinos se encuentran las experiencias europeas de cooperativismos. Por cierto, al ser experiencias de países centrales hegemónicos, están más documentadas y sistematizadas, lo cual permite reconocer sus principios y desarrollo conceptual en distintas corrientes de pensamiento teórico.

\section{Cooperativismo en Europa como concepto moderno y en debate}

Los antecedentes del cooperativismo en Europa se inician en el siglo XVII, con el trabajo titulado "Proposiciones para la creación de una asociación de trabajo de todas las industrias útiles y de la agricultura" 
de John Bellers (1695). Este documento propone los primeros pasos para la conformación de colonias cooperativas de trabajo, en donde los recursos económicos obtenidos del trabajo cooperativo se destinarían a cubrir las necesidades de los socios y a la ampliación y fortalecimiento de la organización. Esta concepción colocaba en el centro al trabajo como riqueza principal de los seres humanos, y al dinero como un medio de intercambio que solo cumplía estrictamente esa función, y que no tenía un carácter acumulable.

Los principios que surgen a partir de esta concepción son los siguientes:

- La idea, bastante desarrollada, de ayudarse a si mismo, que tienen las masas más necesitadas de la población en aras de una vida más humana;

- Realización de dicha ayuda por medio de la unión de pequeñas fuerzas económicas, formando de este modo asociaciones libres;

- Economías colectivas constituidas por tales asociaciones; las funciones económicas de los miembros ligados con la producción y el consumo, se establecen en común por medio de una empresa económica;

- Estructura democrática de dichas asociaciones. En la dirección administrativa de las empresas toman parte todos los socios, los cuales eligen los dirigentes efectivos;

- Idea de la supresión de los intermediarios, que nos son útiles en el engranaje de la vida económica; la ganancia de estos queda para el productor útil;

- Relaciones orgánicas entre la industria y la agricultura, entre la producción y el consumo; y

- La necesidad de pasar a la realización de programas prácticos.

Con estos principios se funda la idea de cooperativismo en Europa. No obstante, solo hasta inicios del siglo XIX, y el desarrollo de las bases económicas del capitalismo, aparece un movimiento de mayor envergadura política e ideológica, que promueve y desarrolla las ideas del cooperativismo como forma de producción hegemónica para la sociedad. Este movimiento es el Socialismo Utópico.

\section{Los aportes de los Socialistas Utópicos a los principios del cooperativismo ${ }^{4}$}

Los denominados socialistas asociacionistas utópicos, como Saint-Simon, Charles Fourier, Robert Owen, William King, Phillipe Buchez, Michel Derrion, Louis Blanc, viniendo de diferentes concepciones teórico políticas al interior del debate del socialismo utópico, se pronunciaron contra la explotación y son considerados, con toda justicia, los precursores del cooperativismo moderno.

Para los socialistas utópicos, la cooperación y el cooperativismo surgen producto de la falta de correspondencia del capitalismo con los intereses de las amplias masas de la población, de su socialización, de sus ideales del bien y la justicia. En ellos hay conciencia de las insatisfacciones que proporciona el capitalismo, de su irracionalidad, y de sus injusticias económicas y sociales.

Deseaban reconstruir la sociedad capitalista desde una perspectiva evolutiva, en una sociedad socialista de base comunitaria. En sus concepciones destaca la acción de la cooperación y el cooperativismo, como forma principal de organización de la sociedad.

Saint Simon (1760-1825) fue partidario de una nueva sociedad económica que denominó "República Cooperativa", en la que el propietario de la producción no fuera el empresario, sino la colectividad. El futuro

4 Esta síntesis descriptiva sobre los aportes de los socialistas utópicos al desarrollo del concepto del cooperativismo se basa en la excelente descripción de IZQUIERDO (s.d.) y de CHAVEZ (2008). 
pertenecía a la asociación universal, con una distribución en correspondencia con las capacidades de cada cual, y todo ingreso como resultado del trabajo; además, el hombre no explotaría jamás a otros hombres.

Para Charles Fourier (1772-1837) el trabajo debería ser en sí mismo agradable y atractivo, además de beneficioso desde el punto de vista económico. Para ello, sostenía la tesis de que todo trabajador debería realizar más de una tarea, a los efectos de evitar la rutina en el trabajo. De hecho, en las pequeñas comunidades de Fourier (falansterios), cada trabajador tenía derecho a elegir el trabajo que quisiera, de acuerdo a sus necesidades. Para ello, las comunidades debían cumplir una serie de requisitos: un número ideal de 1600 personas, con una determinada cantidad de tierra para explotar, un sistema de educación que permitiera que los niños siguieran naturalmente sus inclinaciones y una vida tan en común como las familias quisieran (lo que habilitaba la propiedad privada); se dirigirían democráticamente y se formarían con base en la voluntariedad y la armonía de las diferentes clases sociales; el salario seria reemplazado por el trabajo, asociado con una idílica división de este último; el crédito agrícola y las tiendas comunales serían el paso previo para su constitución etc.

Sin embargo, en vida, Fourier nunca recibió apoyo económico para fundar estas comunidades. De hecho, los primeros falansterios se desarrollaron en Norteamérica, por influjo de Albert Brisbane (1809-1890), quien logra fundar, junto a otros discípulos de Fourier, algunos de éstos sin mayores éxitos, salvo en los casos en que se basaron más en los lineamientos cooperativos propiamente dichos.

Aunque la base de su doctrina no estuvo en las cooperativas sino en el sistema fabril y la educación popular, Robert Owen (1771-1858) es considerado como uno de los más importantes antecesores del movimiento cooperativo. No sólo por lo que hizo en vida, sino también por el hecho que algunos de sus discípulos fundaron la sociedad cooperativa de los "Pioneros de Rochdale".

Este reconocido y atípico empresario soñaba con comunidades de trabajo donde se disolviera por completo la propiedad privada, lo que lo diferenciaba claramente de Fourier. Para Owen, la base de la producción debía ser industrial y agrícola. Sus ideas, no obstante, se irían tiñendo de notorias referencias religiosas (El nuevo mundo moral), lo que lo alejaría de una reflexión más objetiva sobre las potencialidades reales de las comunidades de trabajo.

Los socialistas utópicos se caracterizaron por ser tanto hombres de ideas como de acción. Entre las experiencias concretas inspiradas en estas ideas, debemos citar el caso de las comunidades de New Lanark (Escocia) y las de New Harmony, fundadas por Robert Owen, esta última en EUA en el año 1825. Se considera la comunidad de mayor influencia en el siglo XIX, a pesar de sus innumerables problemas. New Harmony fue pensada por Owen como un modelo igualitario de organización social y económica, capaz de crear riquezas grandiosas, en el que se pudieran inspirar tantas otras experiencias. Si bien tuvo un buen comienzo, las desavenencias pronto empezaron a minar la sustentabilidad del proyecto que finalmente cede en el año 1827.

Las ideas de Owen se popularizaron en el periódico "El Economista" (1821), donde utiliza por primera vez el término cooperativa, en la revista "Crisis" (1832), en la que exalta la idea de la cooperación. A partir de estas ideas y experiencias prácticas, los propios obreros intentaron como solución a la problemática social, llevar a cabo los postulados de Owen. Se organizaron cooperativas de diverso tipo, como también congresos y reuniones para promover estas entidades a nivel internacional.

El médico William King (1786-1865), por su parte, concibió la idea de la cooperación como un medio efectivo de reforma social. En este sentido, consideraba la autoayuda entre los obreros como imprescindible para la acción cooperativa, mediante el aporte de sus asociados. Creó cooperativas de consumo y escuelas de educación cooperativa. 
Michel Derrion (1786-1865), es otro nombre vinculado al desarrollo de las ideas cooperativas. Fundamentó la creación de almacenes cooperativos, al tiempo que consideraba al consumidor como determinante en el desarrollo de las cooperativas, por sentirse estimulado y comprometido con la entidad.

Philippe Buchez (1796-1865) puede ser considerado ciertamente el "padre del cooperativismo francés". Analiza un sistema de principios fundamentales de la cooperación, que se corresponden en su mayoría con las del cooperativismo en general. Planteó el principio de la democracia y la distribución de los ingresos, en correspondencia con el trabajo de cada socio. El criterio era que los trabajadores debían ayudarse entre si y el Estado no debía intervenir, ya que con una buena conducción de la empresa, esta iría creciendo y obteniendo excedentes hasta formar un fondo común para realizar transformaciones en beneficio de la clase obrera. Tenía la idea de un banco Central del Estado para administrar los fondos y transformar la sociedad sobre bases cooperativas.

Las ideas cooperativas tienen repercusión también en el periodista Louis Le Blanc (1812-1882) quien popularizó en Francia las cooperativas obreras de producción. Sus ideas se manifiestan en torno a las relaciones Estado-Cooperativa, a la autonomía de las cooperativas, y a la organización del trabajo.

En síntesis, los aportes de los socialistas utópicos, sobre la conceptualización del cooperativismo se pueden articular en tres premisas esenciales, a saber: i) el derecho de propiedad está fuertemente limitado por el colectivo social; ii) los principales recursos económicos de la sociedad cooperativa están en manos y bajo su control de la masa trabajadora y, iii) su gestión esta dirigida a promover la igualdad y la justicia social (ARICO, apud BOBBIO et al. 1998).

En esta conceptualización histórica del cooperativismo, emerge la experiencia práctica en Inglaterra con la primera empresa cooperativa moderna inscrita como: "Sociedad de los Equitativos Pioneros de Rochdale de 1844" que funda los siete principios fundamentales de movimiento cooperativo, que hasta el día de hoy perduran, a saber; i) libre ingreso y libre retiro; ii) control democrático; iii) neutralidad política, racial y religiosa; iv) ventas al contado; v) devolución de excedentes; vi) interés limitado sobre el capital; y vii) educación continua.

La experiencia de Rochdale mostró la capacidad de organización de la clase trabajadora, marcó el inicio del cooperativismo mundial, demostró la factibilidad de la cooperación desde el punto de vista económico y social, así como la divulgación de la doctrina cooperativa (IZQUIERDO; s.d.). Esto es tan efectivo, que en 1895 se crea la Alianza Cooperativa Internacional - ACI, organización internacional que difunde y promueve los principios de Rochdale, han sido ratificados en 1937 en Viena, en 1966 en Londres y en 1995 en Manchester.

\section{El debate sobre los principios del Cooperativismo.}

Los principios del cooperativismo no han estado exentos de debate y polémica tanto política como ideológica, entre las ideas capitalistas y socialistas de sociedad.

Por un lado, los estudios del cooperativismo pro capitalismo han tendido a ratificarlos como principios económico - productivos, que son compatibles con su forma producción, en tanto el cooperativismo sea neutro políticamente, lo que garantizaría la aplicación del tercer principio de Rochdale. Se define a las sociedades cooperativas como empresas. Su misión central es generar excedentes que permitan a sus dueños - usuarios obtener beneficios económicos, que no obtendrían en forma individual, en una economía rentista como la capitalista. 
Desde la perspectiva de la economía clásica conservadora, unos de sus principales exponentes, J. Stuart Mill, sustenta que el sistema de cooperativas bien articulado en la sociedad capitalista tiene ventajas morales, que expresa en la siguiente afirmación:

“(...) el apaciguamiento del conflicto entre el capital y el trabajo; la transformación de la vida humana, convirtiendo la actual lucha de clases que tiene intereses opuestos en una rivalidad amistosa en la persecución de un bien que es común a todos, la elevación de la dignidad del trabajo; una nueva sensación de seguridad y de independencia en clase trabajadora y el convertir las ocupaciones cotidianas del ser humano en una escuela de simpatías sociales y comprensión practica" (MILL, 1951, p.675).

Esta concepción insiste que la forma de producción cooperativa no es un resorte de cambio de la sociedad capitalista hegemónica; por el contrario, al mantener la imparcialidad de su quehacer económico productivo, social y político es muy funcional para enfrentar las crisis cíclicas del modelo capitalista de producción y sus costos sociales.

Por otro lado, hay quienes han cuestionado el tercer principio de Rochdale, argumentando que la tradición del cooperativismo es de carácter obrero y popular, lo que define a priori su carácter político e ideológico de resistencia y crítica al modelo capitalista dominante. Se plantea que la experiencia histórica del cooperativismo nace de la exclusión de los obreros del sistema productivo basado en el capital. Por tanto, es una respuesta política y social que pone en cuestión al concepto del homus economicus del modelo capitalista. Se articula en la práctica, por medio de la acción de cooperar entre pares, el homus social que tiene como norte el fortalecimiento orgánico de la sociedad, a través de la satisfacción de necesidades económico - productivas y de pertenencia socio cultural. Todo centrado en la aplicación empírica de los principios de igualdad y justicia social.

Marx, en su Manifiesto Inaugural de la Asociación Internacional de los Trabajadores en Londres, 1864, plantea abiertamente la importancia que juega el cooperativismo como forma de resistencia productiva y política al capitalismo:

\footnotetext{
"nos referimos al movimiento cooperativo, y, sobre todo, a las fábricas cooperativas creadas, ...Es imposible exagerar la importancia de estos grandes experimentos sociales que han mostrado con hechos, no con simples argumentos, que la producción en gran escala y al nivel de las exigencias de la ciencia moderna, puede prescindir de la clase de los patronos, que utiliza el trabajo de la clase de las «manos»; han mostrado también que no es necesario a la producción que los instrumentos de trabajo estén monopolizados como instrumentos de dominación y de explotación contra el trabajador mismo; y han mostrado, por fin, que lo mismo que el trabajo esclavo, lo mismo que el trabajo siervo, el trabajo asalariado no es sino una forma transitoria inferior, destinada a desaparecer ante el trabajo asociado que cumple su tarea con gusto, entusiasmo y alegría" (MARX, 1864).
}

Además, el trabajo, ahora asociado, representa un paso más allá del trabajo asalariado, ya que dispensa de la figura del patrón (HADDAD, 2003).

Marx reconoce más adelante en su intervención la tradición utópica del cooperativismo. En sus palabras: “en Inglaterra, las semillas del sistema cooperativista fueron lanzadas por Robert Owen; las experiencias obreras llevadas a cabo en el continente fueron, de hecho, el resultado práctico de las teorías, no descubiertas, pero proclamadas en voz alta en 1848" (MARX, 1864). Este reconocimiento fundamental sitúa la idea de cooperativismo como parte de la discusión político ideológica de la época, entre socialistas y liberales. 


\section{Los aportes teóricos de la crítica social ${ }^{5}$ a la concepción del Cooperativismo}

Los aportes de Marx y Engels a la conceptualización del cooperativismo son significativos. Ambos autores articulan el concepto de cooperativismo analizado desde dos perspectivas. La genético-estructural de autogénesis de la especie humana, en cuanto cooperación social necesaria para la producción de valores de uso, y la de la cooperación histórico-genética dentro de una formación social concreta, la capitalista en nuestro caso, para la producción de valores de cambio bajo condiciones de explotación.

En cuanto a la primera visión, Engels apunta a la siguiente definición orgánica de la sociedad:

"la producción humana alcanza, por tanto, en un determinado estadio, un nivel tal que no sólo satisface las necesidades indispensables a la vida, sino que crea productos de lujo, si bien, al principio, están reservados a una minoría. La lucha por la vida, si, por un instante, queremos conceder algún valor a esa categoría, se transforma en un combate por los goces, no ya sólo por los medios de existencia, sino por medios de desarrollo, por medios de desarrollo producidos socialmente y cooperativamente (ENGELS, 1970 Ed.).

Respecto de la segunda visión, Marx define que el desarrollo del cooperativismo está determinado por la composición estructural de la sociedad capitalista. En sus palabras:

"las fábricas cooperativas de trabajadores, al interior del régimen capitalista, son la primera ruptura de la vieja forma, a pesar de que naturalmente, en su organización efectiva, reproduzcan y tengan que reproducir, por todas partes, todos los defectos del sistema capitalista. Sin embargo, dentro de ellas se suprimió la oposición entre capital y trabajo, aunque todavía apenas bajo la forma en la cual son los trabajadores como asociación los capitalistas de ellos mismos, es decir, aplican los medios de producción para explotar el trabajo propio". (MARX, 1867, 1990 Ed.).

Por tanto, la cooperativa es una negación del capitalismo no lo suficientemente negativa como para proporcionar una superación positiva.

"Es la negación del principal fundamento del sistema, la propiedad privada individual, pero una negación limitada, ya que es promovida al interior del régimen capitalista. Producir en la escala óptima y con la mejor tecnología es la condición de supervivencia de la cooperativa en la competencia con las demás empresas, cooperativas o no, pero no es la garantía de emergencia de una nueva formación social" (HADDAD, 2003).

Retomando el Manifiesto Inaugural de la Asociación Internacional de los Trabajadores, Marx (1864) plantea que:

(...) "al mismo tiempo, la experiencia del período comprendido entre 1848 y 1864 ha probado hasta la evidencia que, por excelente que sea en principio, por útil que se muestre en la práctica, el trabajo cooperativo, limitado estrechamente a los esfuerzos accidentales y particulares de los obreros, no podrá detener jamás el crecimiento en progresión geométrica del monopolio, ni emancipar a las masas, ni aliviar siquiera un poco la carga de sus

${ }^{5}$ Sobre crítica social véase: VILLALOBOS, Mario, Ciencia Social como crítica social. La revolución epistemológica de Karl Marx Primera edición, Colección Ciencias Humanas, Ediciones LOM, 2010. 
miserias. Este es, quizá, el verdadero motivo que ha decidido a algunos aristócratas bien intencionados, a filantrópicos charlatanes burgueses y hasta a economistas agudos, a colmar de repente de elogios nauseabundos al sistema cooperativo, que en vano habían tratado de sofocar en germen, ridiculizándolo como una utopía de soñadores o estigmatizándolo como un sacrilegio socialista. Para emancipar a las masas trabajadoras, la cooperación debe alcanzar un desarrollo nacional y, por consecuencia, ser fomentada por medios nacionales. Pero los señores de la tierra y los señores del capital se valdrán siempre de sus privilegios políticos para defender y perpetuar sus monopolios económicos. Muy lejos de contribuir a la emancipación del trabajo, continuarán oponiéndole todos los obstáculos posibles”.

La perspectiva de este juicio crítico de Marx sobre las concepciones conservadoras del cooperativismo está determinada por el desarrollo histórico de la época y, como ya se ha mencionado anteriormente, es la contraposición a las definiciones economía clásica sobre el concepto. Marx define el cooperativismo como una forma de producción social en transición, y que permite el resquebrajamiento de la base del poder del dueño del capital, de carácter individual.

Según Jacques Texier (2000) en su texto "Democracia, socialismo, autogestión", para resumir la tesis marxista:

\begin{abstract}
"Hay que afirmar que, a pesar de todas las reservas o añadidos necesarios, Marx hace en definitiva un juicio muy positivo sobre las fábricas cooperativas. El razonamiento se articula en la caracterización de las sociedades por acciones desde un doble punto de vista: De una parte, tiene la particularidad de que el capital no es privado sino "social": es una socialización que opera en el marco del sistema capitalista sin abolirlo; es pues una socialización contradictoria, pero que prepara directamente la socialización auténtica del modo de producción de los productores asociados. Y esto tanto más cuanto estas sociedades por acciones son también caracterizadas por la desunión de la propiedad y de las funciones de dirección".
\end{abstract}

De la misma manera, la profundidad conceptual sobre empresas cooperativas y su rol en la jibarización del modelo capitalista de dominación, están determinadas por condiciones reales de dominación a nivel de la superestructura jurídico - política.

"Las cooperativas de productores pueden sobrevivir dentro de la economía capitalista solamente que encuentren la manera de suprimir por algún medio la contradicción capitalista entre el modo de producción y el modo de cambio, lo cual se logrará únicamente librándose artificialmente de la influencia de las leyes de la libre competencia. Su éxito dependerá de que se aseguren de antemano un círculo constante de consumidores, es decir, de que aseguren un mercado constante.” (LUXEMBURGO, 1967, p.73).

Esta posición fortalece la idea que las empresas cooperativas productoras y las consumidoras deben ser competitivas en la producción de sus bienes, por un lado, y de sus servicios, por otro, ya que son los que permiten la distribución de la riqueza producida por la fuerza de trabajo. Se deben articular y coordinar ambos tipos empresas cooperativas, para ser competitivas con respecto a las empresas capitalistas de carácter individual. A partir de estos elementos, se ratifica que el cooperativismo no aparejado a lucha político ideológica, y sometido a los espacios o intersticios que el modelo de acumulación capitalista, solo será una experiencia de fortalecimiento socio - económico, como lo esperan los sectores conservadores de la sociedad.

Por tanto, como plantea Marx, el movimiento cooperativo es una de las fuerzas transformadoras de la sociedad presente, basada en el antagonismo de clases. El gran mérito de este movimiento consiste en 
mostrar que el sistema actual de subordinación del trabajo al capital, sistema despótico que lleva al pauperismo, puede ser sustituido con un sistema republicano y bienhechor de asociación de productores libres e iguales (MARX, 1866).

De la misma manera, se puede destacar al cooperativismo como un movimiento social, que puede contribuir a la transformación de la sociedad capitalista, a pesar de sus limitaciones:

\begin{abstract}
“...el movimiento cooperativo, limitado a las formas enanas, las únicas que pueden crear con sus propios esfuerzos los esclavos individuales del trabajo asalariado, jamás podrá transformar la sociedad capitalista. A fin de convertir la producción social en un sistema armónico y vasto de trabajo cooperativo son indispensables cambios sociales generales, cambios de las condiciones generales de la sociedad, que sólo pueden lograrse mediante el paso de las fuerzas organizadas de la sociedad, es decir, del poder político, de manos de los capitalistas y propietarios de tierras a manos de los productores mismos.”(MARX, 1866).
\end{abstract}

Bajo la misma égida argumentativa, Lenin, por su parte, aborda la problemática del cooperativismo como forma de organización de la producción y de la propiedad. Reflexionó en torno al papel de las cooperativas como instrumento de lucha de la clase obrera, al que consideró un elemento básico para el desarrollo de las fuerzas productivas, en el modelo económico de la transición al socialismo, donde la presencia de una economía mixta era insoslayable. Al propio tiempo, lo concibió como método de administrar y organizar la producción (IZQUIERDO, s.d.). Introdujo dos aspectos novedosos en el análisis de los principios cooperativos hasta ese momento estudiados: la posibilidad del papel rector de la clase obrera en el proceso de Cooperativización, y el apoyo que debía dar el Estado al mismo, sin violar su autonomía.

En el articulo "Sobre la Cooperación", escrito en 1923, la teoría de Lenin sobre el cooperativismo adquiere una mayor conformación. En el mismo enfatiza la importancia de las cooperativas, como una de las premisas para la transformación socialista de la agricultura:

"La significación de las empresas de ese género es inmensa, porque si la hacienda campesina, antes pobre y mísera, continuara viviendo a la antigua ni siquiera se podría hablar entonces de ninguna construcción segura de la sociedad socialista. Sólo en el caso de que se logre mostrar a los campesinos las ventajas del cultivo social, colectivo, asociado, cooperativo de la tierra y sólo si consigue ayudar al campesino por medio de la hacienda asociada, cooperativa, podría la clase obrera, que tiene en sus manos el poder del Estado, demostrar realmente su razón al campesino y atraer realmente hacia ella, de modo firme y efectivo, a la masa integrada por muchos millones de campesinos". (LENIN, 1970).

A diferencia de las cooperativas que surgieron inicialmente en la sociedad capitalista, que lo hicieron para luchar contra el orden económico y social existente, Lenin consideraba que en el socialismo eran una vía para lograr el desarrollo de este.

Destacaba además que la cooperación era indispensable para edificar la sociedad socialista completa. "Eso no es todavía la edificación de la sociedad socialista, pero si es imprescindible y suficiente para esa edificación" (LENIN, 1970).

Desarrolla también de forma creativa, los principios sobre los que se basa el movimiento cooperativo internacional, destacando la necesidad de subordinar los intereses privados a los generales de orden social y de elevar el nivel cultural de los cooperativistas, para llevar a cabo la Cooperativización de forma gradual. Al respecto subraya: “(...) nos queda por hacer una cosa "nada más”, elevar a nuestra población a tal grado de "civilización" que comprenda todas las ventajas de la participación de cada cual en las cooperativas y organice esta participación. Eso y "nada más". Ninguna otra sabiduría es necesaria ahora para pasar al socialismo"(LENIN, 1970). 
En término de síntesis, la mirada de los marxistas entrega elementos críticos a la conceptualización del cooperativismo, que los socialistas utópicos y los cooperativistas pro-capitalismo no desarrollaron, por las limitaciones de su enfoque de análisis y su carácter ideológico. Estos elementos críticos son:

a) El cooperativismo se puede analizar desde dos vertientes epistemológicas de carácter complementaria genético-estructural (Engels) e histórico-genética (Marx).

b) El cooperativismo se define como la primera ruptura de la vieja forma de producción capitalista individual, que pone en tensión la relación capital - trabajo.

c) El cooperativismo, siendo alternativo a la forma de producción, no necesariamente rompe con el modo de producción capitalista.

d) El cooperativismo se define como una forma de producción de transición de carácter social, que permite el resquebrajamiento de la base del poder del dueño del capital de carácter individual.

e) El cooperativismo es una socialización que opera en el marco del sistema capitalista, sin abolirlo; es pues una socialización contradictoria, pero que prepara directamente la socialización auténtica del modo de producción de los productores asociados.

f) El gran mérito de este movimiento cooperativista consiste en mostrar que el sistema de subordinación del trabajo al capital, sistema despótico que lleva al pauperismo, puede ser sustituido con un sistema republicano y bienhechor de asociación de productores libres e iguales.

g) Para convertir la producción social en un sistema armónico y vasto de trabajo cooperativo, son indispensables cambios sociales generales, cambios de las condiciones generales de la sociedad, que sólo pueden lograrse mediante el paso de las fuerzas organizadas de la sociedad, es decir, del poder político, de manos de los capitalistas y propietarios de empresas, a manos de los productores mismos, los trabajadores.

h) La máxima descentralización económico - política productiva en la sociedad se consigue con los sistemas de producción cooperativa. Una persona un voto.

i) El cooperativismo, como forma de organización de la producción y de la propiedad, es indispensable para edificar una nueva sociedad de carácter democrático, igualitario y de justicia social, es decir, una democracia avanzada de base socialista.

\section{Gestión Social}

El tema central de este acápite es definir el referencial teórico sobre Gestión Social, y posteriormente articularlo en las conclusiones con las definiciones de economía solidaria, descentralización y cooperativismo.

Para definir Gestión Social debemos articular diversos conceptos, que permitirán sintetizar de mejor manera su estructura y validación conceptual.

La gestión social tiene una raigambre conceptual vinculada al concepto de desarrollo local - territorial con un sujeto ciudadano (sociedad civil) que participa y decide. Se entiende como aquella acción coordinada entre la sociedad y el poder público municipal, instituida por medio de un proceso participativo y democrático, en pro del bienestar social, económico, político y cultural de un territorio dado.

Desarrollo local es un proceso centrado en un territorio concreto, en el cual los protagonistas son una pluralidad de actores que ocupan determinadas posiciones en el espacio social, y que establecen relaciones en función de objetivos y proyectos comunes. 
Ciudadanía deliberativa quiere significar que la legitimidad de las decisiones políticas debe tener origen en procesos de discusión, orientados por los principios de la inclusión del pluralismo, de la igualdad participativa, de la autonomía y del bien común. Así, la integración de estos dos conceptos implica la redefinición de los parámetros tradicionales de la gestión pública local, esto es, pasar de una gestión centralizada en el poder Ejecutivo municipal (alcalde y sus secretarios) y Legislativo (Cámara o Concejo de Concejales) hacia una gestión descentralizada, en la cual los diferentes grupos que componen la sociedad local interactúen con el poder público, en beneficio de la comunidad.

Una de las premisas que facilitan el proceso de desarrollo local por medio de decisiones concertadas de modo deliberativo entre la sociedad civil, el mercado y el poder público, es la proximidad entre la autoridad pública y la población. Las políticas públicas proyectadas bajo la interacción sociedad-Estado en territorios donde los actores están más próximos, tienen mayor posibilidad de adecuación a las necesidades identificadas.

Contraria a esta posibilidad de interacción sociedad-Estado es la actitud gestora local denominada por Claus Offe de "monística y anticuada", que son aquellos ordenes institucionales fundados sólo en el protagonismo del Estado, del mercado, de la sociedad civil. Las soluciones de los diseños institucionales volcados al desarrollo local deben tomar en cuenta la composición de esos tres componentes poder público, sociedad civil y mercado en la medida en que cada uno de ellos depende del otro y son "modos ideales-típicos en los cuales las personas viven e interactuan" (OFFE, 1999). El autor explica que la necesidad de coordinación entre los tres elementos se da en función de que "cada uno de ellos activa y de cierta forma se basa en una de las tres capacidades colectivamente relevantes por medio de las cuales los seres humanos pueden intervenir en el mundo social" (OFFE, 1999). Cada uno de esos componentes busca maximizar un valor: en el caso del Estado, "comprendiendo derechos y deberes"; en el caso del mercado, la "libertad de elección"; en el caso de las comunidades, "la identidad y su preservación (por medio de compromisos, solidaridad y lealtad)". Así, los procesos de desarrollo local no pueden basarse en una opción monística, o monológica, puesto que ella tiende a no considerar las contribuciones que los otros dos componentes tiene para ofrecer. Como también la combinación no puede ocurrir sólo entre dos elementos, sean Estado-mercado, Estado-sociedad civil o mercado-sociedad civil. Es necesario que ninguno se sobreponga al otro o que lo elimine.

El problema de diseñar y defender relaciones Estado-sociedad, (...) no está en simplemente escoger uno de los tres patrones de forma simplista, sino que de comprometerse, o, en la pero hipótesis, tolerar un proceso de diseño [de] reajuste y sintonización fina (...) en el cual los tres tengan papeles variables que se limiten entre sí. La capacidad de inventar, implementar y tolerar esas "colchas de retal" (...) es la marca del civismo o del "comportamiento cívico", esto es, la habilidad y la voluntad de los ciudadanos de utilizar deliberación abierta y pacífica, así como métodos institucionales para enfrentar los conflictos sociales y políticos (OFFE, 1999).

La construcción institucional [hacia el desarrollo local], no puede ser más conducida por [burócratas o tecnócratas]. El papel-llave para el diseño y la preservación del orden social, por lo tanto, debe ser [también] ocupado por los ciudadanos y sus propias asociaciones cívicas. En un mundo institucional esencialmente confuso, precisamos de juicios públicos informados y compromiso cívico deliberativo, al contrario de conocimiento especializado que sólo ejerza autoridad en lo que se refiere a lo que hacer y a lo que no hacer (OFFE, 1999)

Desde la misma perspectiva, Paula plantea que:

Aquí también se considera que el desarrollo económico no resuelve el problema político de la elección y de la decisión. Como se trata del problema decisorio, el problema está relacionado a la esfera de la administración, resguardando la línea tenue que separa gestión 
y política. Una vez que hay una tradición de delegar a la burocracia estatal la decisión y la implementación de las políticas públicas, cuando se inserte la participación popular es fundamental discutir lo que pertenece al dominio de la gestión y al dominio de la política: las decisiones son políticas, pero precisan tener en consideración variables técnicas: la implementación es gerencial, pero implica administración de conflictos e intereses que pertenecen a la esfera política (PAULA, 2005).

Varias son las posibilidades metodológicas para que el proceso de interacción sociedad civil, mercado y poder público pueda venir al encuentro de las necesidades de un lugar ${ }^{6}$. Hay un componente en todo ese contexto, sin embargo, que debe ser siempre considerado como fundamental para que el desarrollo con ciudadanía sea exitoso: es el de participación que “(...) supone una relación en que actores, usando recursos disponibles en los espacios públicos, hacen valer sus intereses, aspiraciones y valores, construyendo sus identidades, afirmándose como sujetos de derecho y obligaciones" (TEIXEIRA, 2000, p. 37). De ese modo, participar es privilegiar acciones concertadas entre sociedad civil, mercado y Estado, con respecto a aquello que la comunidad acredita como importante en su lugar. La participación tiene que ver con el proceso, con el "como", los resultados son consecuencias de la acción concertada entre los agentes sociales, económicos y estatales.

El tema de la participación se inserta en la nueva polarización de los ideales democráticos. El neoliberalismo, por medio del modelo de "democracia legal", defiende la concepción del Estado-mínimo en su actuación en la sociedad y en la vida privada, dando voz a una expansión de la economía de mercado, según una línea no sólo de cuestionamiento del Estado de bienestar y de la democracia de masas, sino también de escamoteamiento de las desigualdades sociales y de las asimetrías de poder y de recursos ${ }^{7}$. En el otro polo, en tanto, está la concepción de "democracia participativa", que resalta la necesidad de incorporar otros niveles de poder más allá del Estado, pretendiendo a la ampliación de la interacción entre este y la sociedad. Ese modelo tiene como cimientos el principio de que el derecho al desarrollo sustentable puede ser alcanzado en una sociedad participativa, que promueva la idea de eficacia política, teniendo preocupación con los problemas de carácter social y que pueda contribuir para la formación de una ciudadanía calificada capaz de mantenerse permanentemente interesada en el proceso de gobierno (HELD, apud JACOBI, 2000).

Siendo así, la proposición sería una sociedad capaz de intervenir y hacerse presente en el Estado. Al contrario de la propuesta neoliberal de que el Estado deje de intervenir en la economía y en la sociedad, las comunidades locales necesitan señalar y dominar como gestión de sus gobiernos la capacidad y práctica del diálogo entre la sociedad civil, el capital y el gobierno local (OLIVEIRA, 1995). A continuación transcribiremos tres referencias que refuerzan esta proposición:

(a) Es precisamente en el nivel local, en el ámbito cotidiano, donde se ejercen los derechos de ciudadanía, donde la gestión de bienes y servicios urbanos [y rurales] implica una relación directa entre [el gobierno] local y los usuarios, donde se pone a prueba la

Al respecto de esas posibilidades metodológicas Evelina Dagnino (2002, p.10) en "Sociedad civil y espacios públicos en Brasil" comenta: "Una consecuencia concreta fundamental de esas visiones han sido la emergencia de experiencias de construcción de espacios públicos (cursiva de la autora), tanto de aquellos que pretenden promover el debate amplio en el interior de la sociedad civil sobre temas/intereses hasta entonces excluidos de una agenda pública, como de aquellos que se constituyen como espacios de ampliación y democratización de la gestión estatal. Estamos aquí refiriéndonos a la implementación, a lo largo de la última década, de los varios consejos, foros, cámaras sectoriales, presupuestos participativos, etc."

7

Bajo la concepción neoliberal el "Estado aparece de villano; el mercado, de panacea. Todos los males parecen poder ser resueltos por la apertura de la economía, por la disminución del Estado y/o por la concentración de sus gastos. (...) el neoliberalismo acaba por exigir una profesión de fe en las virtudes del capitalismo y de la libre competencia, no más por una cuestión de opción ideológica, en obediencia a una dada visión del mundo, sino por una cuestión de respeto a las cosas 'tales como ellas son'” (PAULANI, 2005, p. 125-126). 
democracia territorial, donde la participación social puede incidir en el planeamiento e implementación de las políticas públicas (ZICCARDI, 1996, p.15)

(b) La idea es que políticas públicas formuladas y ejecutadas localmente tienen mayor posibilidad de adecuación a las necesidades y diversidades de la población, así como ser mejor controladas y evaluadas, posibilitando a la comunidad participar como protagonista de su propio desarrollo (SCHOMMER, 2003, p.105)

(c) Tendríamos así una administración pública co-gestionaria que funcionaría por las alternativas creadas por la ingeniería institucional para la participación popular en la definición de programas, proyectos y gestión de servicios públicos. Eso implica reformular la organización del Estado y elaborar nuevos ordenes institucionales que estimulen prácticas democráticas. Vale resaltar que la ampliación de la institucionalidad política también sería acompañada de un fortalecimiento de la comunidad cívica (PAULA, 2005).

Los fundamentos de la gestión social se aproximan a aquellos pregonados por la democracia deliberativa de Habermas, una vez que el fundamento de su proceso de toma de decisión presupone la participación de todos los actores sociales, que de forma directa o indirecta tengan relaciones con la temática en cuestión. Los actores sociales a ser involucrados - el Estado, la sociedad y el mercado - son, potencialmente, los protagonistas del proceso, discutiendo, democráticamente, sus intereses en busca del entendimiento. "Por lo tanto, en el contexto de la gestión social (...), los actores, al hacer sus propuestas, no pueden imponer sus pretensiones de validez sin que haya un acuerdo alcanzado comunicativamente en el cual todos los participantes expongan sus argumentaciones" (TENÓRIO, 2004). Por último, Tenório caracteriza la gestión social en tanto práctica que

(...)se contrapone a la gestión estratégica en la medida en que intenta sustituir la gestión tecnoburocrática, monológica, por una administración participativa, dialógica, en la cual el proceso decisorio es ejercido por medio de diferentes sujetos sociales. (...) En el proceso de gestión social, (...) la verdad sólo existe si todos los participantes de la acción social [en el espacio público] admiten su validez, esto es, verdad es la promesa de consenso racional o, la verdad no es una relación entre el individuo y su percepción del mundo, pero si un acuerdo alcanzado por medio de la discusión crítica, de la apreciación intersubjetiva [entre los diferentes actores presentes en el proceso]. (TENÓRIO, 2004).

\section{Conclusiones: la Articulación Conceptual entre Economía Solidaria, Descentralización, Cooperativismo y}

\section{Gestión social.}

Esta síntesis articula e integra los conceptos analizados crítica y constructivamente en este trabajo. No existe la intención de dar por cerrado el debate y la argumentación. Por el contrario, se trata de cumplir con el objetivo de ordenar argumentativamente una propuesta de modernización socio - político económica, que se sustente en los actores sociales de base, en términos generales, una democracia de abajo hacia arriba. Se intenta avanzar en el desarrollo de una base conceptual modernizadora y democratizadora de nuestra sociedad, recogiendo la discusión de avanzada que en parte importante de países de América Latina se comienza a practicar con disimiles resultados.

Revisadas las bases epistemológicas de economía solidaria y su vinculación a la descentralización socio político - económica, se plantea que su vinculo conceptual articulador es la participación de las trabajadoras y trabajadores en las decisiones propias de la producción y la redistribución de sus resultados. Por tanto, es una forma de organización productiva altamente vinculada a la democracia participativa y protagónica de los sujetos sociales. Con esto se fortalece la democracia en los ámbitos políticos, sociales, económicos, 
culturales e identitarios de los actores sociales de base, logrando la máxima expresión de descentralización político-administrativa de un Estado republicano.

La vinculación conceptual entre la economía solidaria, la descentralización y el cooperativismo, está determinada por dos elementos centrales de este último. Primero, el cooperativismo, como forma de producción, se caracteriza como un modelo que releva los valores de la solidaridad, igualdad e integración de los dueños de la fuerza de trabajo, elementos que están en el debate conceptual de la economía solidaria. Segundo, la participación directa de los productores en las decisiones de una cooperativa, logrando con esto fortalecer el concepto de descentralización, entendido como autonomía de decisión y capacidad propia de desarrollo de los actores frente al Estado centralizador y autocrático.

De la misma forma, la gestión social se articula con las ideas de la economía solidaria y la descentralización, a partir de fundamentos compartidos. La gestión social se fundamenta en un sujeto social de carácter ciudadano (sociedad civil) que participa y decide en un ámbito territorial, en pro del desarrollo de su comunidad. Se entiende aquella acción como integración democrática entre la sociedad y el poder público local, instituida por medio de un proceso participativo y democrático, en la búsqueda deliberada del bienestar social, económico, político, medioambiental y cultural de su territorio. Estos elementos son participes de la concepción de la economía solidaria y la descentralización. Es importante señalar que el concepto de gestión social aporta el elemento territorial, clave para que los sujetos sociales puedan conformar sus comunidades, y de esa manera vinculen a la estructura político - administrativa local.

Por último, la vinculación conceptual de la gestión social con el cooperativismo, está en que ambas son formas de producción social y se sustentan en la participación de los actores sociales en las decisiones sobre qué y cómo hacer. Por tanto, profundizan la democracia y la modernizan bajo los principios de la participación activa de los sujetos socio-políticos. De hecho, la forma de gestión de una organización cooperativa tiene su referente en la gestión social, siempre y cuando sea democrática y deliberativa, como lo plantea la gestión social en su matriz de principios.

\section{Referencias}

APEL, K.O. en Simon - Shäfler y Zimmerli (Eds.). Wissenschaftheorie der Geisteswissenschaftten. Hamburgo: Hoffman und Campe, 1975. Traducción de J. M. Mardones en "Filosofía de las ciencias humanas y sociales: Materiales para una fundamentación científica”. Barcelona, Anthropos, 1991.

ARroyo, J. Economia Popular e Solidária. In: MEdeIROS, A.; MARTINS, P. H. (Org.) Economia Popular e Solidária - Desafios Teóricos e Práticos. Recife: Bagaço, 2003.

BOBBIO, N., et al. Diccionario de Política. Madrid, España, Siglo XXI Editores, 1998.

CHAVEZ, L. C. "Laboratórios Sociais de Autogestão no Brasil e na Argentina: Cooperativas na produção e reprodução da vida em cooperação". Tese Doutorado Programa de Pós-Graduação em Sociologia Política do Centro de Filosofia e Ciências Humanas, Universidade Federal de Santa Catarina, Florianopolis, 2008.

CORAGGIO, J. L. Da economia dos setores populares à economia do trabalho. Questões debatidas In: KRAYCHETE, G. et al. (Org.) Economia dos setores populares: entre a realidade e a utopia. Petrópolis: Vozes, p. 91-141, 2000.

. “La economía social como vía para otro desarrollo social”. Documento preparado para el lanzamiento del debate sobre "Distintas propuestas de Economía Social". Disponible en http://www.urbarded.ungs.edu.ar, acceso en marzo 2011. Publicado en la Biblioteca Virtual TOP.

DAGNINO, E. (Org.). “Sociedade civil e espaços públicos no Brasil”. São Paulo: Paz e Terra, 2002. 
ENGELS, F. “El problema Campesino en Francia y Alemania”. 1875. Obras Completas; Moscú: Editorial Progreso, 1970 ed.

• “Del socialismo utópico al socialismo científico”. Obras Completas; Moscú: Editorial Progreso, 1970 ed.

HABERMAS, J. Ciencia y técnica como ideología. Madrid: TECNOS, 1984.

HADDAD, F. "Sindicalismo, cooperativismo y socialismo". In BORON, A. "Filosofía política contemporánea". Controversias sobre civilización, imperio y ciudadanía. Argentina: CLACSO, 2003.

ICAZA, A. M. S.; TIRIBA, L. "Economía popular”. In: CATTANI, A. D. (Org.) “A outra economía”. Porto Alegre: Editora Veraz, 2003.

IZQUIERDO, C. "El cooperativismo una alternativa de desarrollo a la globalización neoliberal para América Latina: una visión desde la identidad cooperativa". Disponible en http://www.eumed.net acceso em marzo 2011. s.d.

JACOBI, P. “Políticas sociais e ampliação da cidadania”. Rio de Janeiro: FGV, 2000.

LENIN, V. I. “Sobre la Cooperación”. Obras Completas. Tomo 45. Moscú: Editorial Progreso, 1970.

. “Socialismo y cooperativismo”. Compilación de escritos. Euskadi: Ediciones Cooperativistas, 1972.

LUXEMBURGO, R. “Reforma o Revolución”. Colección 70. México S.A.: Editorial Grijalbo, 1970.

MARIATEGUI, J.C. "7 Ensayos de interpretación de la realidad Peruana”. Buenos Aires: Biblioteca del Pensamiento Crítico Latinoamericano, Edición 2009.

MARX, K. "Instrucción sobre diversos problemas a los delegados del Consejo Central Provisional.” In: MARX, K.; ENGELS, F. “Obras Escogidas”, Tomo II, Moscú: Editorial Progreso, 1974 a.

- "Manifiesto Inaugural de la Asociación Internacional de los Trabajadores". In: MARX, K.; ENGELS, F. “Obras Escogidas", Tomo II, Moscú: Editorial Progreso, 1974 b.

• “El Capital”. Tomo 1. Moscú: Editorial Progreso, 1867, 1990 ed.

MILL, J.S. “Principios de Economía Política”. México: Fondo Cultura Economica, 1951.

OFFE, C. “A atual transição da história e algumas opções básicas para as instituições da sociedade”. In: PEREIRA, L: BRESSER, C. et al. (Org.). "Sociedade e Estado em transformação". São Paulo: Editora UNESP; Brasília: Enap, 1999.

OLIVEIRA, F. "Reforma do Estado e democratização do poder local” In: VILLAS-BÔAS, R.; TELLES, V., (Org.). "Poder local, participação popular; construção da cidadania”. São Paulo: Fórum Nacional de Participação Popular nas Administrações Municipais, p. 5-10, 1995.

PAULA, A. P. P. de. “Por uma nova gestão pública”. Rio de Janeiro: FGV Editora, 2005.

PAULANI, L. “Modernidade e discurso económico”. São Paulo: Boitempo, 2005.

SANTOS, B. de S.; RODRÍGUEZ, C. "Introdução: para ampliar o cânone da produção" In: SANTOS, B. de S. (Org.). "Produzir para viver: os caminhos da produção não capitalista". Rio de Janeiro: Civilização Brasileira, 2002.

SCHOMMER, P. C. "Gestão pública no Brasil: notícias do teatro de operações”. Revista de Administração de Empresas, v. 43, out./dez., p. 102-107, 2003.

SINGER, P. "Economia solidária: um modo de produção e distribuição". In: SINGER, P., SOUZA, A. (Org.). "A Economia solidária no Brasil; a autogestão como resposta ao desemprego". Sao Paulo: Ed. Contexto, 2000. 
RAZETO, L. “Los caminos de la economía de solidaridad”. Buenos Aires: Ediciones Lumen-Humanitas, 1997a.

- "Factor C", (Conferencia de Luis Razeto en la Escuela Cooperativa Rosario Arjona- CECOSESOLA), Venezuela, 1997 b disponible en http://www.economiasolidaria.net. Acceso en marzo 2011.

. "La economía de solidaridad: Concepto, realidad y proyecto ¿pueden juntarse la economía y la solidaridad?" Revista Persona y Sociedad, v. 13, nº 2, agosto, p. 97-110, 1997.

TEIXEIRA, E. C. “Sociedade civil e participação cidadã no poder local”. Salvador: UFBA, 2000.

TEIXEIRA, J., “Democracia, Socialismo y Autogestión”. La Pensée, n 321, enero/ marzo, 2000.

TENÓRIO, F. G. “O mito da participação”. Revista de Administração Pública, Rio de Janeiro, v. 24, n. 3, maio/jul., p. $162-164,1990$. Unijuí, 2004.

“Um espectro ronda o terceiro setor, o espectro do mercado: ensaios de gestão social.” 2. ed. rev. Ijuí, Ed.

; ROZENBERG, J. “Gestão pública e cidadania: metodologias participativas em ação”. Revista de Administração Pública, Rio de Janeiro, v. 31, n. 4, jul./ago, p. 101-125, 1997.

VILLALOBOS, M. "Ciencia Social como crítica social. La revolución epistemológica de Karl Marx”. 1. Ed., Santiago de Chile: Ediciones LOM, 2010.

ZICCARDI, A. (Coord.). "La tarea de gobernar: gobiernos locales y demandas ciudadanas". México (D. F.): IIS/UNAM, 1996. 